\title{
Recovery Capacity, Haemodynamic and Blood Lactate Changes during Training and Competition in Elite Congolese Karate Athletes
}

\author{
Jean Georges André Moulongo ${ }^{1 *}$, Jean Martin Moussoki ${ }^{1}$, Elvina Lys Surêche Massamba ${ }^{2}$, \\ Fêtra Nella Massala Kitanga1, Bernard Packa Tchissambou ${ }^{1}$, Jean Robert Mabiala Babela ${ }^{3}$, \\ Alphonse Massamba ${ }^{1}$
}
${ }^{1}$ Laboratory of Sport Biosciences and Combat Sports Research Unit, Higher Institute of Physical Education and Sports, Marien NGOUABI University, Brazzaville, Congo
${ }^{2}$ Laboratory "Health and Adapted Physical Activities", Higher Institute of Physical Education and Sports, Marien NGOUABI University, Brazzaville, Congo
${ }^{3}$ Pediatrics Department, Brazzaville University Hospital and Faculty of Health Sciences, Marien NGOUABI University, Brazzaville, Congo

Email: *jgamoulongo@gmail.com

How to cite this paper: Moulongo, J.G.A. Moussoki, J.M., Massamba, E.L.S., Massala Kitanga, F.N., Packa Tchissambou, B., Mabiala Babela, J.R. and Massamba, A. (2020) Recovery Capacity, Haemodynamic and Blood Lactate Changes during Training and Competition in Elite Congolese Karate Athletes. World Journal of Cardiovascular Diseases, 10, 257-273. https://doi.org/10.4236/wjcd.2020.105024

Received: February 5, 2020

Accepted: April 27, 2020

Published: April 30, 2020

Copyright () 2020 by author(s) and Scientific Research Publishing Inc. This work is licensed under the Creative Commons Attribution International License (CC BY 4.0).

http://creativecommons.org/licenses/by/4.0/ (c) (i) Open Access

\begin{abstract}
Background: Rare are the studies which treated the effect of training and successive fights of karate on haemodynamic and blood lactate concentrations responses. Objectives: To evaluate and analyze the aerobic capacity of elite Congolese karate athletes, as well as their haemodynamic and blood lactate concentrations responses changes during Ruffier test and stimulated competition. Methods: Twelve karate athletes (6 seniors and 6 juniors) took part in the study. These karate athletes were selected within the national karate teams (senior and junior) of Congo-Brazzaville. Anthropometric, bioenergetic and haemodynamic (HR, SBP, DBP) parameters and blood lactate [La] concentrations were measured at rest, immediately after the end of Ruffier test and each fight $(n=3)$. Results: Peak aerobic power (PAP) and maximum oxygen uptake $\left(\mathrm{VO}_{2} \max \right)$ values averaged $437 \pm 23$ watts and $57.61 \pm$ $2.2 \mathrm{ml} / \mathrm{kg} / \mathrm{mn}$, values varying as function as age division (senior vs junior). The recovery index was $5.4 \pm 3.4$ for juniors and $6.8 \pm 3.2$ for seniors. SBP, $\mathrm{HR}$ and [La] concentrations increased significantly during fights, compared to the resting values. $\mathrm{HR}_{\max }$ was $182.3 \pm 1.6 \mathrm{bpm}\left(89 \%\right.$ theoretical $\left.\mathrm{HR}_{\max }\right)$ for seniors and $182.0 \pm 13.5 \mathrm{bpm}\left(86 \%\right.$ theoretical $\left.\mathrm{HR}_{\max }\right)$ for juniors. Peak [La] concentrations were $10.3 \pm 1.5 \mathrm{mmol} / \mathrm{l}$ for seniors and $10.8 \pm 1.2 \mathrm{mmol} / \mathrm{l}$ for juniors. Conclusion: Congolese karate athletes call upon high levels of the
\end{abstract}


anaerobic and aerobic capacities. The karate training program in Congo should emphasize more gold improvising lower body anaerobic power and endurance.

\section{Keywords}

Karate, Peak Aerobic Power, Maximum Oxygen Uptake, Heart Rate, Blood Lactate

\section{Introduction}

Karate is a martial art of Japanese origin, attack and defense using the arms and legs [1] [2]. Very popular sport, the goal of its practice is to impose itself on the other by carrying out a decisive action (ippon or more advantage) while striking in a vital point or making give up. Karate was a demonstration sport in the Olympics Games before becoming year official sport in the 2020 Olympics Games in Tokyo. The time-motion analysis and heart rate and blood lactate responses to the fights suggested that karate competition places high demands on one short-term anaerobic power and ability to recovery [3]. The research of performance for a practitioner is characterized by complex problems. Thus, the increasing knowledge of the physiological phenomena brought into play in the high level sporting preparation makes it possible to better define its effects and to control its progression. The organized competition of weight category rests on fights of min duration each one; the surface of competition is $64 \mathrm{~m}^{2}(8 \mathrm{~m}$ on side). Consequently, the techniques used with the maximum of effectiveness and power ask for training of often high intensity, including running, endurance and muscular resistance exercises, series of kicks techniques, strike blows techniques of fist and edge of hand. For good to involve itself, one thus makes recourse mainly to the anaerobic metabolic way, but also to the aerobic way [2]. It is in this context that several studies have been undertaken in karate black belt athletes for more than 20 years [4] [5] [6] [7] [8]. In Congo, the studies devoted to the haemodynamic responses to exercise at the martial arts practice are rare [9] and the heart rate observed during meetings in the majority of the competitive sports is always very high [10]. In the margin of these observations, the medical follow-up of sportsmen taking share with the tests registered with the official calendar of the competitions of the Congolese Karate Federation is irregular, even specific. It is to fill this gap that we carried out a metabolic and cardiovascular follow-up in the karate athletes, during the preparation of the national championship. Thus, this exploratory work evaluates haemodynamic and blood lactate concentrations responses during the training and the fights in Congolese karate athletes according to the age category. The objectives of this study were: 1) to evaluate and analyze peak aerobic power (PAP) and maximum oxygen consumption $\left(\mathrm{VO}_{2} \max \right)$ of Congolese karate athletes; 2$)$ to determine their re- 
covery capacity, following a submaximal exercise; 3 ) to evaluate and analyze the variations of heart rate, blood pressure and blood lactate concentrations throughout fights. The interest of this study is to be able to draw the conclusions on level of regulation and control of training of karate in the African environment.

\section{Material and Methods}

\subsection{Topics}

The study, observational and experimental, was carried out from September 27 2019 to October 92019 in Brazzaville, Congo-Brazzaville. The sample of study was made up starting from the karate athletes qualified with the national karate championship. To participate in this study, a clinical examination and an electrocardiogram made it possible to determine the following medical history: neuropathy, unstable angina, history of effort syncope, tight aortic stenosis or obstructive cardiomyopathy; karate athletes not presenting these exclusion criteria and those not carrying associated pathologies or cardiorespiratory complications were selected. Other exclusion criteria were: taking medication that could affect metabolism or change body; participation in a rapid weight loss (2\% - 10\%) program for competing in a designated weight category. Twelve sportsmen, all black belts and no smokers, were included in the study after written informed agrees. They were distributed according to the age in 6 seniors (20 - 30 years, $24.7 \pm 3.5$ years) and 6 juniors (16 - 19 years, $17.1 \pm 1.2$ years). They have 7 years of training experiment. Seven subjects took part in at least an international competition, the others with a national tournament. Among the first subjects, among then two of the subjects had obtained a silver medal to African Games 2015. The study received the approval of the National Committee of Ethics for Research in Health Sciences. Employment status of each subject was assessed by the question, "Are you currently working?". Consumption of alcohol was determined based on the respondent's declaration of drinking alcohol (not drinking or formerly drinking alcohol). Participants were also categorized for smoking status as current smokers, ex-smokers, and non-smokers.

During the period of study, the time volume of training was 15 hours per week, at a rate of 3 hours per day, to Monday on Friday. A training session was generally made up of three parts: physical preparation, technico-tactic specific training to karate (including fights) and recovery period. The physical training (duration one hour per meeting) associated limbering up exercises, games, muscular exercises and jogging (from 30 - 45 minutes during Sunday). The athletes who did not enjoy a perfect health at the time the study and at least 3 months before, and the irregular athletes at training sequences were excluded from the study. Concerning the technico-tactic training, HR, SBP, DBP and lactatemia were measured at half-course and at the end of precompetitive period; the meetings proceeded to $70 \%-99 \%$ of theoretical $\mathrm{HR}_{\max }$. Durations of meetings were in conformity with those recommended by the International Karate Federation, in the two categories of age. 


\subsection{Methods}

\subsubsection{Anthropometric Measurements}

Anthropometric measurements consisted of the determination of weight using electronic balance to nearest $100 \mathrm{~g}$ (Seca Instruments Ltd., Hamburg, Germany), height and percentage of fatty mass (\% FM) evaluated from the 4 cutaneous skinfolds (biceps, triceps, subscapular, iliac-crest) using Harpenden caliper (Lange, Cambridge, MA, USA), according to formula of Durnin and Rahaman [11]. The arm length was measured the wrist circumference. Leg length was measured from the midpoint of line joining the uppermost circumference to the iliac crest, down the minimum circumference above the ankle.

\subsubsection{Heart Rate and Arterial Pressure Measurements}

HR measurements were taken during Ruffier test and a series of fights. Ruffier test made it possible to evaluate the cardiac recovery capacity of a subject following a submaximal exercise. Ruffier test [12] is a moderated test, comprising 30 inflections-extensions of legs carried out in 45 seconds, that is to say 10 inflections in 15 seconds. The rhythm of exercise is given by a metronome. An observer takes care of the good execution of the movement, which must be made vertical bust. At the end of Ruffiertest, recovery index (RI) was calculated using formula: RI $=(\mathrm{HR} 0+\mathrm{HR} 1+\mathrm{HR} 2) / 10$. Value HR0 is HRat rest expressed in beats per minute, HR1 the HR measured immediately at the end of exercise and HR2 the HR raised to 1 minute for the recovery period. The scale of appreciation of IR is recommended by the American College of Sports Medicine [13]. With regard to measurements, HR was recorded uninterrupted during 3 consecutive fights of 2 min 30 duration, separated by one minute, using portable cardiofrequencemeter (Polar accurex + , Kempel, Finland). Measurements of HR at the time of the fights were realised on an interval of $5 \mathrm{~s}$ during 24 fights per age category, that is to say 2 fights per subject. This made it possible to better distinguish the phases from actions and the phases of rest during fights. SBP and DBP values were recorded at rest, after Ruffier test and after each fight using a Spengler tensiometer by the procedure Riva-Rocci.

\subsubsection{Aerobic Capacity}

A continuous exercise with increasing load on ergocycle allowed the determination by direct measurement of $\mathrm{PAP}$ and $\mathrm{VO}_{2}$ max, using an automated system of measurement of gaseous exchanges (CPX, Medical Graphics, Munich, Germany). The test started with a heating of $3 \mathrm{~min}$ to 30 watts. For the determination of PAP, cycling frequency was fixed at $75 \mathrm{rpm}$, the power at the first stage was 75 $\mathrm{w}$, and the increments at $30 \mathrm{w}$. Duration at the first stage was $4 \mathrm{~min}$ and that of the 2 minute old following. The test was stopped when the subject did not manage anymore to maintain imposed cycling frequency, in spite of the lavished encouragements. PAP value corresponds to the power supported at the last stage of this test. However, when this one was stopped before its term. Value of selected power was calculated according to following procedure: 


$$
\mathrm{PAP}=\mathrm{P}_{\text {complete }}+\Delta \mathrm{P} \times \mathrm{t} / \mathrm{t} \text { stage }
$$

where $\mathrm{P}_{\text {complete }}$ is the power at the last stage carried out completely, $t$ the time of cycling put at the last incomplete stage, $t$ stage the time of a complete stage and $\Delta \mathrm{P}$ the increment of power for each stage.

With regard to determination of $\mathrm{VO}_{2}$ max, the load increased by $30 \mathrm{w} / \mathrm{min}$ except at the end of the test where the increase was reduced to $20 \mathrm{w} / \mathrm{min}$ in order to approach in a precise way measurement of the maximal parameters. A valid $\mathrm{VO}_{2}$ max was obtained when at least 2 of these 3 criteria were met: 1) plateau in $\mathrm{VO}_{2}$ lower than $200 \mathrm{ml} / \mathrm{min}$ in spite of increasing work rate, 2) maximal $\mathrm{HR}>$ $90 \%$ of predicted theoretical maximum $\mathrm{HR}$ according to formula [14]: $\mathrm{HR}_{\max }=$ 220 - age \pm 10 , and 3 ) respiratory exchange ratio of $\geq 1.10$.

\subsubsection{Lactate Measurements}

Blood lactate concentrations were measured using the instructions of the KDK Corporation (Lactate Pro-LT 1710, Tokyo, Japan). The taking away were carried out on the level of the index, at rest and at the end of each fight. All measurements were carried out in an identical way with the same material, according to the same protocol and in the same room of fight.

\subsection{Research Design}

During the experimentation, each subject was regarded as its own witness. A meeting of familiarization with the experimental protocol and the material was carried out for each subject. At this meeting of familiarization, the unfolding of fights was carried out with a cardiofrequencemeter similar to that used in the experimentation. If $\mathrm{VO}_{2} \max$ were measured at a subject at rest before the series of fights, $\mathrm{HR}_{\max }$, SBP and DBP were measured at rest and during the phases of fight. Each subject carried out a fight with the same partner of the same weight category. Each karate meeting included/understood a cardiovascular activation, an articular and muscular heating, and a specific heating of karate. Lastly, the 2 $\min 30$ of fight took place. The time of fight being an effective time, it was proceeded to a chronometric statement of the durations of the various phases of work and recovery to facilitate the analysis of results. The combat organized in return ticket were spaced one day. To work out the situations of karate fight, we took into account two constraints: on the one hand the brittleness of portable cardiofrequencemeter and on the other hand, the concern of preserving the uncertainty (characteristic of the combat sports which gives the possibility for the two protagonists of gaining).

\subsection{Statistical Analysis}

Data are expressed on mean \pm standard deviation. The comparison of two means was carried out using Student $t$ test for paired series. The variations of $\mathrm{HR}, \mathrm{SBP}$ and DBP values, [La] concentrations between the rest and the end of each fight were examined by an ANOVA with one way and 4 factors. Thereafter, the post hoc Scheffe test made it possible to specify between which levels these 
differences were exactly. Differences were considered statistically significant when $\mathrm{p}<0.05$. Statistical analysis was performed using the SPSS/PC Statistical Social Package for Science (version 23.0).

\section{Results}

\subsection{Anthropometric Data}

Examination of morphological data (Table 1) shows a significant difference $(\mathrm{p}<$ 0.05 ) for height and weight, in favour of the seniors. Difference was not significant for body fat percent, BMI, leg length and arm length.

Table 1. Group anthropometrics, sociodemographic and clinical characteristics of subjects.

\begin{tabular}{|c|c|c|}
\hline & Seniors $(n=6)$ & Juniors $(n=6)$ \\
\hline \multicolumn{3}{|l|}{ Anthropometric data } \\
\hline Height (cm) & $170.4 \pm 3.9$ & $163.5 \pm 3.4$ \\
\hline Weight (kg) & $65.1 \pm 2.6$ & $58.3 \pm 3.8$ \\
\hline BMI $\left(\mathrm{kg} / \mathrm{m}^{2}\right)$ & $22.4 \pm 1.2$ & $22.8 \pm 1.3$ \\
\hline Leg length $(\mathrm{cm})$ & $98.2 \pm 2.7$ & $95.4 \pm 3.5$ \\
\hline Arm length $(\mathrm{cm})$ & $76.3 \pm 2.2$ & $73.5 \pm 3.4$ \\
\hline Body fat (\%) & $11.2 \pm 2.2$ & $10.7 \pm 2.2$ \\
\hline \multicolumn{3}{|l|}{ Demographic data } \\
\hline \multicolumn{3}{|l|}{ Employment status } \\
\hline Yes & 6 & 2 \\
\hline No & 0 & 4 \\
\hline Years at school, mean (SD) & $16.43(3.57)$ & $10.59(2.11)$ \\
\hline \multicolumn{3}{|l|}{ Educational status } \\
\hline High school & 04 & 05 \\
\hline University & 02 & 01 \\
\hline \multicolumn{3}{|l|}{ Clinical status } \\
\hline \multicolumn{3}{|l|}{ Alcohol intake, n (\%) } \\
\hline Drinker & $02(100)$ & 00 \\
\hline Former drinker & $01(100)$ & 00 \\
\hline Non drinker & $03(33.4)$ & $06(66.6)$ \\
\hline \multicolumn{3}{|l|}{ Smoking } \\
\hline Current smoker & $01(100)$ & 00 \\
\hline Ex-smoker & $01(100)$ & 00 \\
\hline Non smoker & $04(40)$ & $06(60)$ \\
\hline
\end{tabular}

Abbreviation: BMI, body mass index. 


\subsection{Cardiovascular Data}

$\mathrm{HR}, \mathrm{SBP}$ and DBP values at rest (Table 2) were no significant, no statistical difference was found between seniors and juniors. Differences of mean values of RI were also no significant (Table 2).

HR, SBP and DBP values at rest and at the end of Ruffier test are presented in Table 3. The increasing rate of HR during Ruffier test was $+48.7 \%$ at the seniors and $+50 \%$ among juniors in comparison to $\mathrm{HR}$ at rest. It was also raised of the significant differences $(\mathrm{p}<0.001)$ on the level of SBP at the end of the test. SBP values reached $132.8 \pm 1.4 \mathrm{mmHg}$ in seniors and $134.3 \pm 3.2 \mathrm{mmHg}$ among juniors, as deviation respectively of $20.8 \%$ and $15.0 \%$ compared to the value at rest.

\subsection{Aerobic Capacity}

PAP and $\mathrm{VO}_{2}$ max values are shown in Table 4. These values were similar in two age divisions. However, the high values were found in senior athletes, except for $\mathrm{VO}_{2}$ max reported to weight $(3.59 \pm 0.24 \mathrm{l} / \mathrm{min}$ for juniors vs $3.41 \pm 0.27 \mathrm{l} / \mathrm{min}$ for seniors).

\subsection{Evolution of Heart Rate during Fights}

The evolution of the HR during 3 fights is described in Figure 1. The post-hoc

Table 2. Values of recuperation index and cardiovascular parameters at rest.

\begin{tabular}{cccc}
\hline & Seniors $(\mathbf{n}=6)$ & Juniors $(\mathbf{n}=6)$ & $\mathbf{P}$ \\
\hline $\mathrm{HR}_{0}(\mathrm{bpm})$ & $76.2 \pm 9.4$ & $72.7 \pm 11.3$ & $\mathrm{NS}$ \\
$\mathrm{SBP}_{0}(\mathrm{mmHg})$ & $118.2 \pm 10.2$ & $116.7 \pm 9.3$ & $\mathrm{NS}$ \\
$\mathrm{DBP}_{0}(\mathrm{mmHg})$ & $85.6 \pm 1.6$ & $87.1 \pm 1.3$ & $\mathrm{NS}$ \\
$\mathrm{RI}$ & $6.8 \pm 3.2$ & $5.4 \pm 3.4$ & $\mathrm{NS}$
\end{tabular}

Abbreviations: $\mathrm{HR}_{0}$, heart rate at rest; $\mathrm{SBP}_{0}$, systolic blood pressure at rest; $\mathrm{DBP}_{0}$, diastolic blood pressure at rest; RI, recuperation index.

Table 3. Values of heart rate, systolic blood pressure and diastolic blood pressure at rest and at the end of Ruffier test.

\begin{tabular}{cccc}
\hline & Rest & End of Ruffier test & P \\
\hline SR (bpm) & Seniors $(\mathbf{n}=6)$ & & \\
SBP (mmHg) & $76.2 \pm 8.3$ & $148.6 \pm 10.3$ & $<0.05$ \\
DBP (mmHg) & $118.2 \pm 4.2$ & $132.8 \pm 2.5$ & $<0.001$ \\
& $85.6 \pm 1.6$ & $87.8 \pm 1.2$ & NS \\
HR (bpm) & Juniors $(\mathbf{n}=6)$ & & $<0.05$ \\
SBP (mmHg) & $72.7 \pm 7.5$ & $145.3 \pm 9.7$ & $<0.001$ \\
DBP (mmHg) & $87.1 \pm 1.3$ & $134.3 \pm 3.2$ & NS \\
\hline
\end{tabular}

Abbreviations: HR, heart rate; SBP, systolic blood pressure; DBP, diastolic blood pressure. 
Table 4. Bioenergetic characteristics of subjects.

\begin{tabular}{ccccc}
\hline & $\begin{array}{c}\text { All group } \\
(\mathrm{n}=12)\end{array}$ & $\begin{array}{c}\text { Seniors } \\
(\mathrm{n}=6)\end{array}$ & $\begin{array}{c}\text { Juniors } \\
(\mathrm{n}=6)\end{array}$ & $\mathrm{P}$ \\
\hline PAP (watts) & $437 \pm 23$ & $440.7 \pm 24.2$ & $433.3 \pm 21.8$ & $>0.05$ \\
$\mathrm{VO}_{2} \max (\mathrm{ml} / \mathrm{kg} / \mathrm{min})$ & $57.6 \pm 2.2$ & $58.5 \pm 1.8$ & $56.7 \pm 2.6$ & $>0.05$ \\
$\mathrm{VO}_{2} \max (\mathrm{l} / \mathrm{min})$ & $3.50 \pm 0.25$ & $3.41 \pm 0.27$ & $3.59 \pm 0.24$ & $>0.05$ \\
\hline
\end{tabular}

Abbreviations: $\mathrm{PAP}$, peak aerobic power; $\mathrm{VO}_{2}$ max, maximum oxygen consumption.

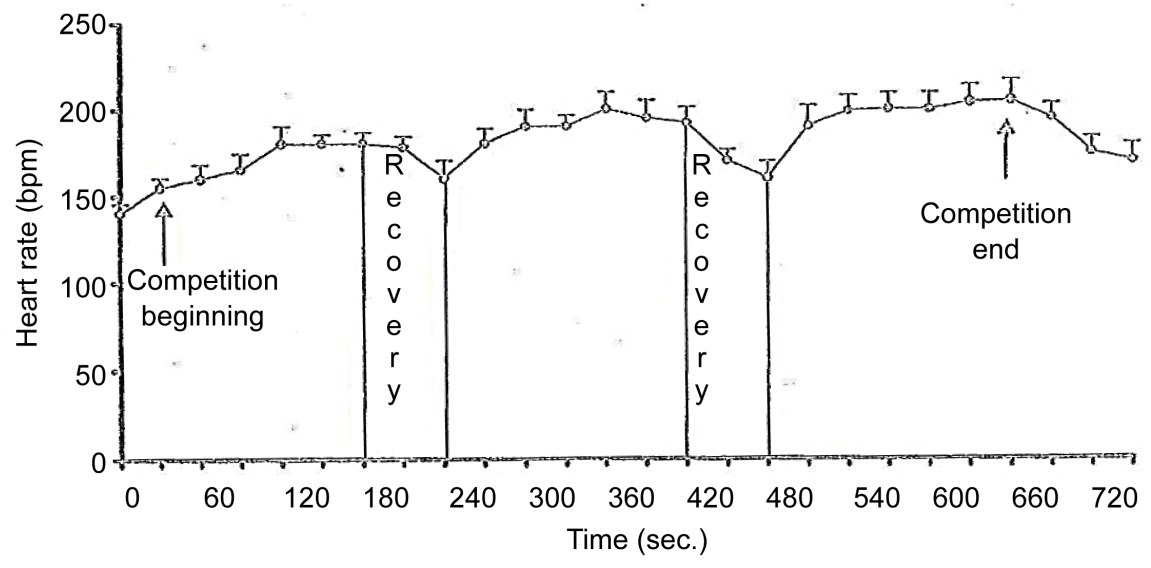

Figure 1. Evolution of heart rate during 3 fights sequences.

analysis showed that as compared to HR values at rest, HR increased significantly between first and third fights in the two age groups, to reach $185.3 \pm 2.2$ bpm in the senior athletes $(\mathrm{F}=15.2 ; \mathrm{p}<0.001)$ and $181.7 \pm 1.5 \mathrm{bpm}$ among juniors $(\mathrm{F}=16.5 ; \mathrm{p}<0.001)$, in comparison to values at rest. The rough $\mathrm{HR}$ obtained at the end of the third fight represented high percentages compared to the theoretical $\mathrm{HR}_{\max }$. No significant difference was found between juniors and seniors at the time of various fights [end of $1^{\text {st }}$ fight: $152.4 \pm 20.1$ (72\%) bpm vs $160.3 \pm 19.4(78 \%) \mathrm{bpm}$; end of $2^{\text {nd }}$ fight: $180.4 \pm 12.6(85 \%) \mathrm{bpm}$ vs $175.8 \pm$ $14.1(86 \%) \mathrm{bpm}$; end of $3^{\text {rd }}$ fight: $182.0 \pm 13.5(86 \%) \mathrm{bpm}$ vs $182.3 \pm 13.6(89 \%)$ bpm].

\subsection{Evolution of Blood Pressure during Fights}

In the whole of the subjects, SBP values increased significantly compared to the values at rest (Figure 2). It was observed exercise effect $(\mathrm{F}=7.81 ; \mathrm{p}<0.006)$ and age effect $(F=5.17 ; p<0.003)$. However, ANOVA revealed a non-significant increase in DBP values during fights in comparison to values at rest (Figure 3). The exercise effect and the age effect were not found.

\subsection{Evolution of Concentrations of Blood Lactates}

Blood lactate concentrations (Figure 4) increased significantly during fights among juniors $(\mathrm{F}=22.7 ; \mathrm{p}<0.001)$ and seniors, compared to resting values $(1.8 \pm$ $0.4 \mathrm{mmol} / \mathrm{l}$ vs $1.7 \pm 0.2 \mathrm{mmol} / \mathrm{l}$ respectively). However, there was no significant 


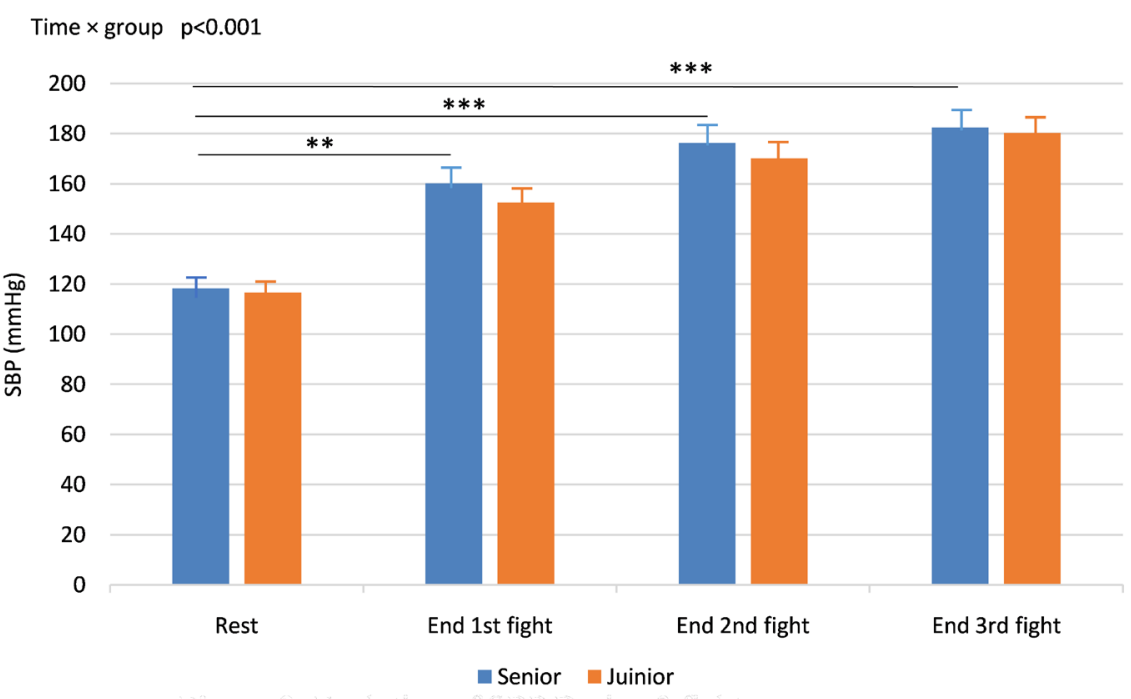

Figure 2. Evolution of SBP during 3 fights sequences. ${ }^{* *}: \mathrm{p}<0.01 ;^{* * *}: \mathrm{p}<0.001$.

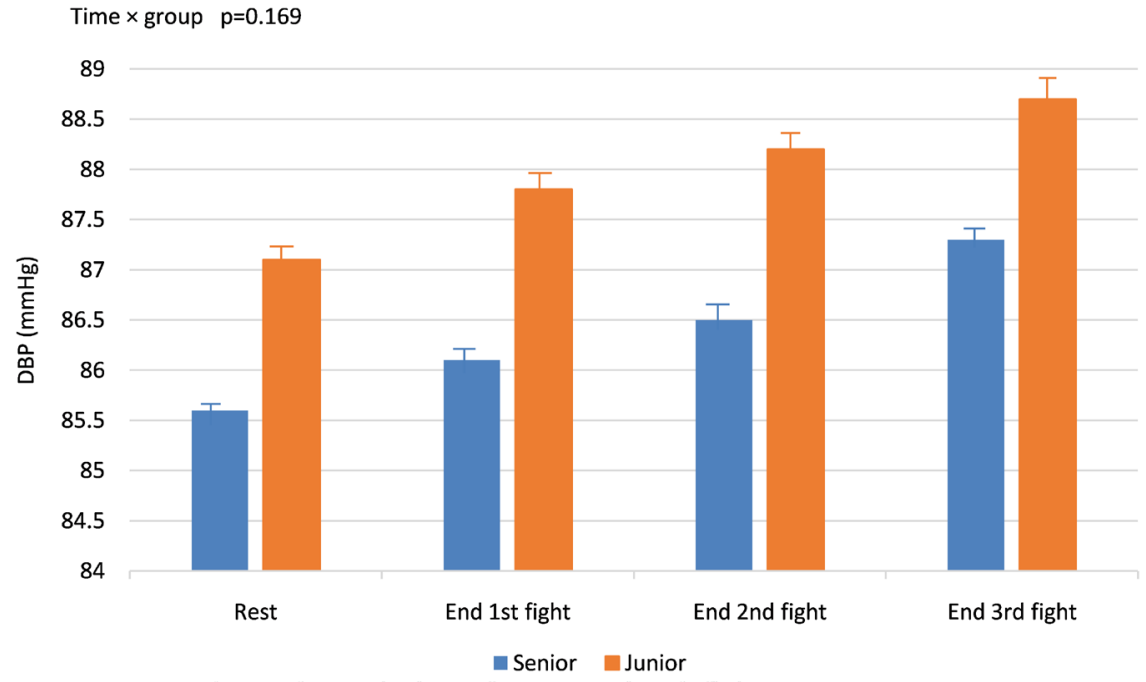

Figure 3. Evolution of DBP during 3 fights sequences.

difference of [La] concentrations between juniors and seniors at the time of the various fights [end of 1stfight: $5.3 \pm 0.7 \mathrm{mmol} / \mathrm{l}$ vs $4.9 \pm 0.5 \mathrm{mmol} / \mathrm{l}$; end of 2ndfight: $7.2 \pm 1.0 \mathrm{mmol} / \mathrm{l}$ vs $6.8 \pm 0.5 \mathrm{mmol} / \mathrm{l}$; end of 3rdfight: $10.8 \pm 1.2$ $\mathrm{mmol} / \mathrm{l}$ vs $10.3 \pm 1.5 \mathrm{mmol} / \mathrm{l}]$.

\section{Discussion}

This study shows mainly that the specific karate exercises and the simulated competition significantly affect the evolution of HR, SBP and [La] concentrations in the athlete. Data obtained reveal that age, weight and height of our subjects (Table 1) are comparable with those reported by the literature in subjects involved to the martial arts [15] [16] [17]. However, our values (height, PAP and $\mathrm{VO}_{2} \max$ ) are lower than those of taekwondo athletes reported by Bouhlel et al. 


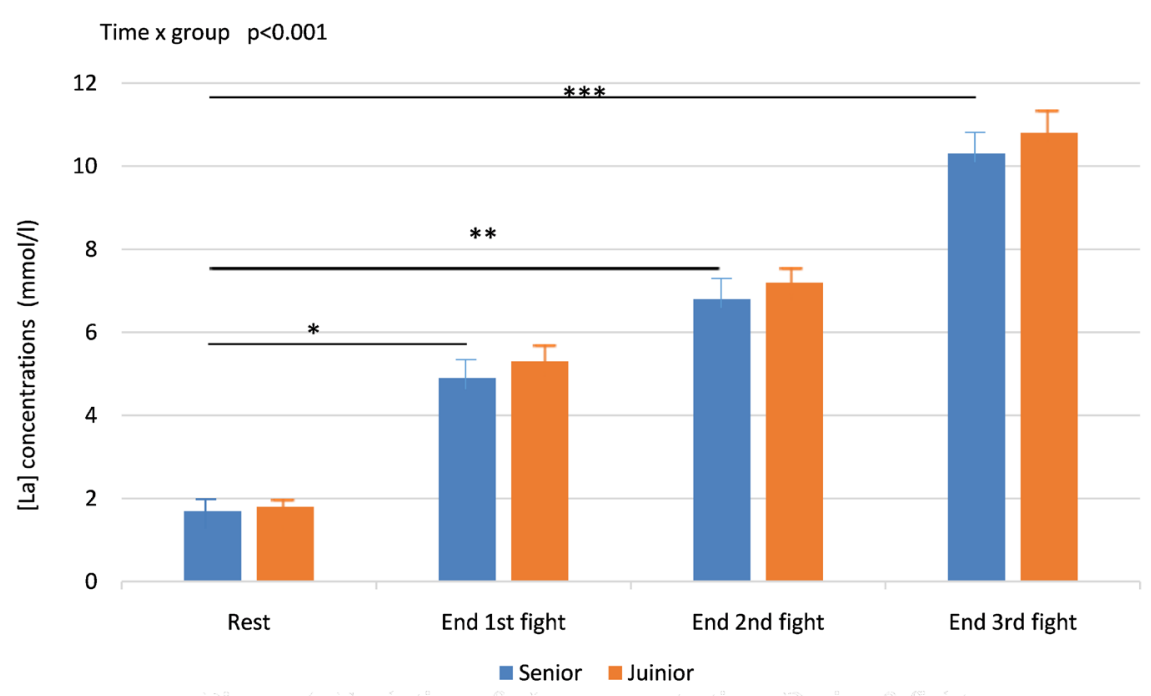

Figure 4. Evolution of [La] concentrations during 3 fights sequences. ${ }^{*}: \mathrm{p}<0.05 ;{ }^{*}: \mathrm{p}<$ $0.01{ }^{* * *}: \mathrm{p}<0.001$

[18]. Congolese karate athlete is also characterized by a moderate recovery capacity with an mean RI value of 6.1. In our work, we used the Ruffier test to evaluate cardiovascular recovery before the series of the measurements taken at the time of the fights. Several factors explain the choice of this test among several tests available (Trip hammer test, Flack test, Systolic Tension Time, ...).

It is about a dynamic and submaximal test a minima. Its total energy cost in $45 \mathrm{~s}$ estimated at $27.8 \pm 1.95 \mathrm{ml} \mathrm{STPD} / \mathrm{kg}$, cardiac cost at 101 beats (60 to 144) and oxygen debt at $22.2 \pm 5 \mathrm{ml} \mathrm{STPD} / \mathrm{kg}$ [12]. Ruffier test allows, in current medical practice, to detect in sensitive populations blood pressure anomalies (SBP value higher than $280 \mathrm{mmHg}$ ), disorders of rhythm (passage in auricular fibrillation, or tachysystolic auricular) and anginous pains or an honest know-shift of the ST segment. However, duration of test (45 s) and its intensity are major factors which influence recovery, but they are not only. The physical form, food ingestion (post-prandial thermogenesis), familiarity of subjects with the procedures of evaluation, variations of body temperature, catecholamines concentrations, metabolic cost of the use of lactates and substrates, are as many factors which can modify not only $\mathrm{HR}$, but also oxygen uptake. It is cavity that at the time of a muscular exercise, it is very difficult to control the whole of parameters; but we could assure us that each subject consumed neither alcohol, nor cafeine or other substances before Ruffier test and that its sleep was good the night preceding the test. Moreover, we adopted a rhythm of inflections-extensions of legs, compatible with an activity with lactic anaerobic dominant. This protocol made it possible to raise the HR at the end of the test between $110-140 \mathrm{bpm}$ and authorized raised capacities for work, likely not to modify the lactate rate. That undoubtedly explains the good tolerance of exercise observed at our subjects, thanks to a spreading out of the cardiorespiratory constraints over one limited duration. The use of cardiofrequencemeter for the monitoring of $\mathrm{HR}$ in our 
study which can be discussed, achieves the unanimity nowadays because it is a reliable tool for assessment of physical activity intensity in trained athletes and older people who are trying to reduce risk factors for coronary heart disease through exercise [19].

Thus, the adaptation slower to the recovery of our karate athletes testifies to an increase in peripheral resistances, accused in the opposition to the modifications induced by physical exercise. Moreover, it is known that values of the relaxation time differ according to capacities from adaptation in hot medium surrounding [20], one characteristic of our environment during study where the temperatures of ambient air bordered $33^{\circ} \mathrm{C}$. Thus, at these temperatures the time of retardation is lengthened at the less adapted subjects, and the speed with which the restoration of the cardiac function is carried out towards values at rest is lengthened. The exposure of the body to heat then modifies the dynamics of mechanisms of cardiovascular adjustment during post-exercise recovery. However, evaluation of recovery capacity in the sportsman is not sufficient to predict the good physical condition, as specified by the studies of Packa-Tchissambou et al. [21], Vandewalle et al. [22].

Our work also highlighted the superiority of our HR values in comparison to those noted by MassambaMiabaou et al. [23] during African Games 2015 in karate athletes, $62.7 \mathrm{bpm}$ and taekwondo athletes, $61.3 \mathrm{bpm}$, Moulongo et al. [9] in Congolese judo athletes, $64.5 \mathrm{bpm}$, and Artioli et al. [24] in Kung Fu athletes, $59.2 \mathrm{bpm}$. HR values at rest of our subjects (Table 2) were $76.2 \pm 9.4 \mathrm{bpm}$ for seniors and $72.7 \pm 11.3 \mathrm{bpm}$ for juniors, as variation of $4.9 \%$ between two age groups being no significant. Higher values are reported by the literature in sedentary congolese subjects [25] [26], $80.2 \mathrm{bpm}$ and $79.5 \mathrm{bpm}$ respectively. A reduction in HR values at rest is also observed in other experiments. In those brought back by Alexander et al. [27] in the professional football players, HR at rest decreases by a beat per minute, by week of training. The more one is involved, the more HR at rest drops. According to Chatard [28], HR at rest in the individuals who involve themselves regularly is often lower than $50 \mathrm{bpm}$ (effects on sympathetic nerve tonicity), whereas the usual values at the sedentary subjects are higher than $60 \mathrm{bpm}$. Indeed, sinusal bradycardia meets with higher frequency in sporting population than in sedentary population. Its origin is allotted partly to vagal hypertonicity as can develop it the endurance sport, but a genetic factor predisposing seems necessary. Bradycardia is indeed far from being systematic as show it the following statistics. For Camus [29], out of 1000 sportsmen HR is $65 \mathrm{bpm}$ in men and $75 \mathrm{bpm}$ among women, all confused sports; the variations show $\mathrm{HR}$ value in men at $63.5 \mathrm{bpm}$ in athletics, $62.5 \mathrm{bpm}$ in cycling for example, against $70.7 \mathrm{bpm}$ in tennis and $71.2 \mathrm{bpm}$ in the sportsmen practising several sports. In the male athletes, HR varies from 52 to $74 \mathrm{bpm}$, and in tennis players from 60 to $81 \mathrm{bpm}$. For Venerando [30], mean HR values in cyclists were $53 \mathrm{bpm}$ and $71 \mathrm{bpm}$ in no sportsmen; values vary from 47 to $60 \mathrm{bpm}$ in cyclists and from 60 to $81 \mathrm{bpm}$ among sedentaries, which confirms 
the genetic disparity. The bradycardias towards $32,34 \mathrm{bpm}$ quoted with predilection by sporting press are very rare. They are not obligatorily an unquestionable sign of sporting value. Moreover, vagal origin of this bradycardia is confirmed by disorders of sino-auricular and auriculo-ventricular conduction which are sometimes observed. The theory of Reindell [31] making increase in the volume of the heart the cause of deceleration of the rhythm cannot thus be retained, because bradycardia precedes hypertrophy. It is banal, in addition to observe clearly a PR space above $0.17 \mathrm{~s}$ reaching $0.24 \mathrm{~s}$ for moderate bradycardia of $60 \mathrm{bpm}$. Even if we did not study the electrocardiogram of our sportsmen, this fact signs two sinusal and nodal components of ascribable sporting bradycardia to the action of two pneumogastric ones, the right acting preferentially on the node of Keith and Flack, it left on the node of Tawara. However, it is excluded only our high HR values at rest compared to those brought back by the authors quote previously, undoubtedly seem to be associated the bad management of training by the trainers in Congolese context (low volume of training, amateur status of Congolese karate athlete, low lifestyle).

In addition, our data show that the distribution of the blood pressure values at rest (Table 2) does not revealed blood pressure anomalies. Indeed, SBP and DBP mean values at rest, $117.4 \mathrm{mmHg}$ and $87.8 \mathrm{mmHg}$, are close to those reported in a former study in judo athletes [9], $120.0 \pm 1.5 \mathrm{mmHg}$. The tiny variations observed are to be registered with a cardiac adaptation to the muscular exercise, particularly to ventricular hypertrophy (not objectified in our study). Indeed, the cardiac response to exercise represents the integration of efforts of tachycardia, of sympathetic nerve stimulation of the mechanism of Franck-Starling himself related to the increase in the venous return. De Plaen and Detry [32] finds values of $120.4 \pm 1.1 \mathrm{mmHg} / 82.6 \pm 2.3 \mathrm{mmHg}$ for 108 karate athletes aged to $25-34$ years. Meckel et al. [33], in 29 Israeli karate athletes and students in physical education, bring back values of $119.3 \pm 1.8 \mathrm{mmHg} / 83.8 \pm 3.2 \mathrm{mmHg}$. The weekly frequency of training of subjects in the two studies was 5 meetings with one 5 - 6 hours daily duration. In addition, the cardiovascular request has a variable repercussion from one subject to another. Among the accused factors, it acts inter alia of aerobic capacity, aerobic endurance, level of training and technico-tactic level of the subject. At the end of Ruffier test, our SBP values increased significantly among senior athletes $(\Delta=+20.8 \%)$ and juniors $(\Delta=+15 \%)$, whereas DBP values varied little. Thus, a widening of differential (SBP-DBP) was observed. A mechanism likely to explain this change is the increase of cardiac flow with the intensity of exercise.

Moreover, HR values were increasing throughout the 3 fights, ranged between $72 \%-89 \%$ of the theoretical $\mathrm{HR}_{\max }$ (Figure 1). If the fight is the meeting which increases more the rate of heart rhythm, HR increasing is significant as of the 1stfight. This increase is concomitant with those of SBP values (Figure 2) and lactatemia (Figure 4) which are also statistically significant and progressive. The [La] concentrations reach after $420 \mathrm{~s}$ of effective fight $10.8 \pm 1.2 \mathrm{mmol} / \mathrm{l}$ among 
juniors and $10.3 \pm 1.5 \mathrm{mmol} / \mathrm{l}$ in seniors. Heller et al. [15] found peak [La] concentrations after $143 \mathrm{~s}$ fight of $11.4 \mathrm{mmol} / \mathrm{l}$, Bouhlel et al. [18] after $720 \mathrm{~s} 10.2 \pm$ $1.2 \mathrm{mmol} / \mathrm{l}$. High HR response and [La] concentrations observed during fights proved the high intensity of exercise. Indeed, the fight of karate is characterized by sequences that vary from attack (kicks, blows of fist, kicks combined with blows of fist, mowing of legs followed by blows of fist...) and observations of adversary for counter-attacks. The duration of attack varies between $1-5 \mathrm{~s}$, and its intensity is high. Consequently, anaerobic way is strongly requested during the fight. However, the relative share of aerobic metabolism is not yet well elucidated. However, the missing of steady state showed that the energetic demand during 3 fights surpassed the potential of aerobic metabolism and solicited the anaerobic glycolysis [34] [35] [36]. Francescato et al. [37] suggested that the overall energy requirement $\left(\mathrm{VO}_{\text {eq }}\right)$ given by the sum of $\mathrm{VO}_{2}$ and $\mathrm{VO}_{2}$-lactate is very high for the karate style. The zone of aerobic-anaerobic transition determined by a lactatemia from $4 \mathrm{mmol} / \mathrm{l}$ is thus rather close to the maximum effort. All things considered, validation of two criteria out of the three brought back by literature [38], namely: relatively high $\mathrm{VO}_{2}$ max, low lactatemia and $\mathrm{HR}_{\max }$, suggest that our karate athletes developed a significant aerobic endurance by their training.

Finally, a fight of karate can be regarded as an intermittent anaerobic exercise, which is close to the concept of alternatively aerobic and anaerobic activity proposed byDel Monte and Menchinelli [39]. Using kihon and ju-kumite exercise which belong to "the culture" karate athletes, the latter request enormously aerobic way to carry out the gestural economy. However, the competitive preparation requires the development of the anaerobic metabolism because techniques used at the time of fights, ju-kumite and kihon solicit by brief, explosive, intense and fast actions of upper and lower limbs. Analysis of our results leads us to draw conclusions for training. In terms of training for karate in the pre-competitive period, we have noted that the heart rate and the lactatemia vary with the intensity of the fights during the competition. Thus, the coach can relate to a graph HR values-[La] concentrations. We then establish the profile of the homogeneity or the discrepancy of aerobic training. The intermittent test of 2 min $30-60 s-2$ min 30 and successive fights have a good performance. This profile highlights the sectors that must be improved as a priority and the procedures to be used. For example, the trainer can insert in his training cycle one or two microcycles where he would use in priority the intermittent forms of work of the type 2 min - $2 \mathrm{~min}, 3 \mathrm{~min}-3 \mathrm{~min}, 4 \mathrm{~min}-4 \mathrm{~min}$ to reach relatively quickly $2 \mathrm{~min}-30 \mathrm{~s}, 3$ $\mathrm{min}-45 \mathrm{~s}, 4 \mathrm{~min}-1 \mathrm{~min}$. It is therefore a question of efficiency that is to say of the adaptation of systems to a type of effort specific to karate. In addition, we also believe that it is possible to offer high performance senior athletes, particularly to the classic training sessions, sessions favoring short duration and high intensity exercises. In terms of junior training, the content of the sessions must be adapted to meet the physiological demands expressed for this age category. 
Indeed, the use of anaerobic metabolism in adolescents at the end of puberty is strongly recommended. Since the energy expenditure in karate in competitive form requires brief and intense exercises requesting the anaerobic metabolism, it is necessary to be vigilant as for the situations to be set up in the sessions of competitive preparation.

\section{Conclusion}

Our study showed that the karate Congolese experts have a moderate recovery capacity and a required aerobic capacity. The evolution of HR, SBP and [La] concentrations during fights shows the importance of anaerobic and aerobic metabolisms to karate practice. This work thus makes it possible to validate the reliability of variables: $\mathrm{HR}$, SBP, DBP, blood lactate concentrations to discriminate a certain number of karate experts during a selection starting from the cardiovascular and metabolic criteria relevant. Thus, the karate trainer, in the sub-Saharan African environment, can start from these criteria simple and easy to implement to build a system of control of training.

\section{Acknowledgements}

The authors gratefully thank Dr. Martin Mvitu for excellent scientific devices and technical assistance, to Dr. Joseph Bonazebi for statistical treatment. We would like to particularly thank all participants who made by to their authorities and commitment this possible study.

\section{Author Contributions}

MJGA designed the study, participated in the implementation of experimental procedure and wrote the first version of the article. MJM, MELS and MKFN were involved in the acquisition of field data. PTB and MBJR have validated the experimental procedure and reread the first version of article. MA performed the statistical analysis of data and reread the final version of the article that has received the approval of all authors.

\section{Conflict of Interests}

None.

\section{References}

[1] Habersetzer, R. (2010) Guide Marabout de karate. 9th Edition, Denoël, Paris/Bruxelles.

[2] Kordi, R., Maffuli, N., Wrobie, R., et al (2009) Combat Sports Medicine. Springer, London, 21-40.

[3] Del Vecchio, F.B., Hirata, S.M. and Franchini, E. (2011) A Review of Time-Motion Analysis and Combat Development in Mixed Martial Arts Matches at Regional Level Tournaments. Perceptual and Motor Skills, 122, 639-648.

https://doi.org/10.2466/05.25.PMS.112.2.639-648 
[4] Brito, C.L., Castro Martino Roas, A.F., Souza Brito, I.S., et al (2012) Methods of Body Mass Reduction by Combat Sports Athletes. The International Journal of Sport Nutrition and Exercise Metabolism, 22, 89-97. https://doi.org/10.1123/ijsnem.22.2.89

[5] Cynarski, W.J. and Kudlaez, M. (2008) Injuries in Martial Arts and Combat Sports: A Comparative Study. Archives of Budo, 4, 91-97.

[6] Gutiérez-Garcia, C., Perez Gutiérez, M. and Svinoh, J. (2010) Martial Arts of the World. An Encyclopedia of History and Innovation. California ABC-Clio (Santa Barbara), 1, 181-191.

[7] Yard, E.E. and Knox, C.L. (2007) Pediatric Martial Arts Injuries Presenting to Emergency Departments. United States 1990-2003. Journal of Science and Medicine in Sport, 10, 219-226. https://doi.org/10.1016/j.jsams.2006.06.016

[8] Junge, A., Engebretsen, L., Mountjoy, M.L., et al (2009) Sports Injuries during the Summer Olympic Games 2008. The American Journal of Sports Medicine, 37, 2165-2172. https://doi.org/10.1177/0363546509339357

[9] Moulongo J.G.A., Massamba, E.L.S., Massamba, A. and Packa Tchissambou, B. (2016) Effects of Voluntary Apnea on Haemodynamic Responses during Groundwork Techniques of Judo. World Journal of Cardiovascular Diseases, 6, 300-311. https://doi.org/10.4236/wjcd.2016.69034

[10] Campos, F.A., Bertuzzi, R., Dourado, A.C., et al (2012) Energy Demands in Taekwondo Athletes during Combat Simulate. European Journal of Applied Physiology, 112, 1221-1228. https://doi.org/10.1007/s00421-011-2071-4

[11] Durnin, J. and Rahaman, M. (1976) The Assessment of the Amount of Fat in the Human Body from Measurements of Skinfold Thickness. British Journal of Nutrition, 21, 681-689. https://doi.org/10.1079/BJN19670070

[12] Ruffier, J.E. (1951) Considérations sur l'indice de résistance du cœur à l'effort. $M e$ decine, Education Physique et Sport, 3, 7-12.

[13] American College of Sports Medicine (2017) ACMS's Guidelines for Exercise Testing and Prescription. 10th Edition, Wolters Kluwer, Singapore.

[14] Kenney, W.L., Wilmore, J.H. and Costll, D.L. (2015) Physiology of Sport and Exercise. 6th Edition, Human Kinetics, Champaign, IL.

[15] Heller, J., Peric, T., Dlouha, R., Kohlikova, E., Melichna, J. and Vakova, H. (1998) Physiological Profiles of Male and Female TDK Black Belt. Journal of Sports Sciences, 16, 243-249. https://doi.org/10.1080/026404198366768

[16] Zabukovec, R. and Tiidus, P.M. (1995) Physiological and Anthropometric Profile of Elite Kickboxers. Journal of Strength and Conditioning Research, 9, 240-242. https://doi.org/10.1519/00124278-199511000-00007

[17] Degoutte, F., Jouanel, P. and Filaire, E. (2004) Solicitation of Protein Metabolism during a Judo Match and Recovery. Science \& Sports, 191, 28-33. https://doi.org/10.1016/S0765-1597(03)00162-X

[18] Bouhlel, E., Jouini, A., Gnada, N., Nefzi, A., Ben Abdallah, K. and Tabka, Z. (2006) Heart Rate and Blood Pressure Responses during Taekwondo Training and Competition. Science \& Sports, 21, 285-290. https://doi.org/10.1016/j.scispo.2006.08.003

[19] Karapetian, G.K., Engels, H.J. and Gretebeck, R.J. (2008) Use of Rate Variability to Estimate LT and VT. International Journal of Sports Medicine, 29, 652-657. https://doi.org/10.1055/s-2007-989423

[20] Cuesta, T.M. and Singer, M. (2012) The Stress Response and Critical Illness: A Review. Critical Care, 40, 3283-3289. https://doi.org/10.1097/CCM.0b013e31826567eb 
[21] PackaTchissambou, B., Massamba, A., MabialaBabela, J.R., Oniangue, R., Bahanguila, B.A., GnamaMankoti, G., et al (2002) Recovery from Exercise in Trained Smokers. Annales de Cardiologie et d Angéiologie, 51, 327-335. [In French] https://doi.org/10.1016/S0003-3928(02)00146-4

[22] Vandewalle, H., Sebert, M.P., Alimoradian, S. and Monod, H. (1984) Bioénergétique du test de Ruffier. Med Sport, 58, 244-249.

[23] MassambaMiabaou, D., Moulongo J.G.A., KimpamboudiMatondo, A.V., Massamba Cola, S.I.J. and Massamba, A. (2017) Combat Sports Injuries in Well-Trained Athletes during African Games 2015 in Brazzaville, Congo. Advances in Physical Education, 7, 274-285. https://doi.org/10.4236/ape.2017.73022

[24] Artioli, G.G., Gualano, B., Franchini, E., et al (2009) Physiological, Performance, and Nutritional Profiles of the Brazilian Olympic Wushu (Kung Fu) Team. Journal of Strength and Conditioning Research, 23, 20-25. https://doi.org/10.1519/JSC.0b013e318187687a

[25] WHO (2000) World Health Report. Geneva, Switzerland.

[26] KimballyKaky, G., Gombet, T., Bolanda, J.D., Voumbo, Y., Okili, B. and EllengaMbolla, B. (2006) Prévalence de l'hypertension artérielle à Brazzaville. Cardiol Trop, 32, 43-45.

[27] Alexander, D., da Silva, C.D., Hill-Hass, S., Wong, del P., Natali, A.J., De Lima, J.R., et al (2012) Heart Rate Monitoring in Soccer: Interest and Limits during Competition Match Play and Training, Practical Application. Journal of Strength and Conditioning Research, 26, 2890-2906. https://doi.org/10.1519/JSC.0b013e3182429ac7

[28] Chatard, J.C. (2005) Sport et santé: Quelle activité physique pour la santé. Publications de l'Université de Saint-Etienne, 82.

[29] Camus, G. (2011) Electrocardiogramme du sportif. Bilan de 1000 examens. Thèse de médecine Faculté de Médecine de Nantes, France.

[30] Venerando, A. (1979) Electrocardiography in Sports Medicine. The Journal of Sports Medicine and Physical Fitness, 19, 107-113.

[31] Reindell, H. (1960) Herzkrelslaufkrankheiten und sport. Johann Ambrosius Barth, Munchen.

[32] De Plaen, J.F. and Detry, J.M. (1990) Hemodynamic Effect of Physical Training in Arterial Pressure. Acta Cardiologica, 85, 479-88.

[33] Meckel, Y., Ekshtein, A., Tsuk, S. and Eliakim, A. (2019) Pre-Exercise Subjective Estimation of Heart Rate in Different Physical Activities among Physical Education Students. Advances in Physical Education, 9, 42-52. https://doi.org/10.4236/ape.2019.91004

[34] Di Prampero, P.E. (1981) Energetics of Muscular Exercise. Reviews of Physiology, Biochemistry and Pharmacology, 89, 143-222. https://doi.org/10.1007/BFb0035266

[35] Thompson, W.R. and Vinueza, C. (1991) Physiological Profiles of Male and Female Taekwondo Black Betts. Sports Medicine, Training and Rehabilitation, 3, 49-53. https://doi.org/10.1080/15438629109511939

[36] Vallier, J.M., Brisswalter, J. and Hanon, C. (1995) Evaluation du métabolisme de la boxe anglaise de haut niveau de performance. Science \& Sports, 10, 159-162. https://doi.org/10.1016/0765-1597(96)89364-6

[37] Francescato, M.P., Talon, T. and Di Prampero, P.E. (1995) Energy Cost and Energy Source in Karate. European Journal of Applied Physiology, 71, 355-361. https://doi.org/10.1007/BF00240417

[38] Pellegrino, R., Viegy, G., Brusasco, V., Crepo, R.E., Burgos, F., Casaburi, R., et al 
(2006) Série du groupe de travail ATS/ERS: "Standardisation des explorations fonctionnelles respiratoires". Stratégies d'interprétation des explorations fonctionnelles respiratoires. Revue des Maladies Respiratoires, 23, S79-S104.

https://doi.org/10.1016/S0761-8425(06)71981-7

[39] Del Monte, A. and Menchinelli, C. (1986) Aspettifisiologicidelkarate. Medicine and Sport, 39, 103-111. 